\title{
Über Kathodenstrahlen
}

\section{Nobel-Vortrag}

\author{
gehalten in
}

öffentlicher Sitzung der Königl. Schwedischen Akademie der Wissenschaften zu Stockholm

\author{
von \\ P. Lenard
}

Zweite, durch viele Zusätze vermehrte Auflage mit 11 Abbildungen

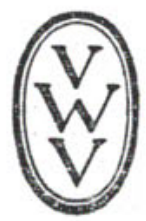

Berlin und Leipzig 1920

Vereinigung wissenschaftlicher Verleger Walter de Gruyter \& Co. 
Alle Rechte, einschlieBlich des Übersetzungsrechts, vorbehalten. 